\title{
Publisher Correction: CFD-based modelling of phase transformation in laser welded low-carbon steel
}

\section{Aleksander Siwek $^{1}$}

Published online: 25 June 2021

(C) The Author(s) 2021

\section{Correction to: Welding in the World}

https ://doi.org/10.1007/s40194-021-01130-2

Due to a mistake during production, the publication of this article unfortunately contained a mistake in Equations 6 and 7. Please see the correct equations below.

$$
\begin{gathered}
\gamma=\gamma_{m}^{\circ}-A\left(T-T_{m}\right)-R T \Gamma_{S} \ln \left[1+k_{1} c_{i} e^{-\left(\Delta H^{\circ} / R T\right)}\right] \\
\frac{\partial \gamma}{\partial T}=-A-R \Gamma_{S} \ln \left[1+K c_{i}\right]-\frac{K c_{i}}{\left(1+K c_{i}\right)} \frac{\Gamma_{S} \Delta H^{\circ}}{T} \\
K=k_{1} e^{-\left(\Delta H^{\circ} / R T\right)}
\end{gathered}
$$

The original article has been corrected.

Publisher's note Springer Nature remains neutral with regard to jurisdictional claims in published maps and institutional affiliations.

The online version of the original article can be found at https://doi.org/ 10.1007/s40194-021-01130-2

\footnotetext{
Aleksander Siwek

Aleksander.Siwek@agh.edu.pl

1 AGH University of Science and Technology, Al. Mickiewicza 30, 30-059 Kraków, Poland
} 